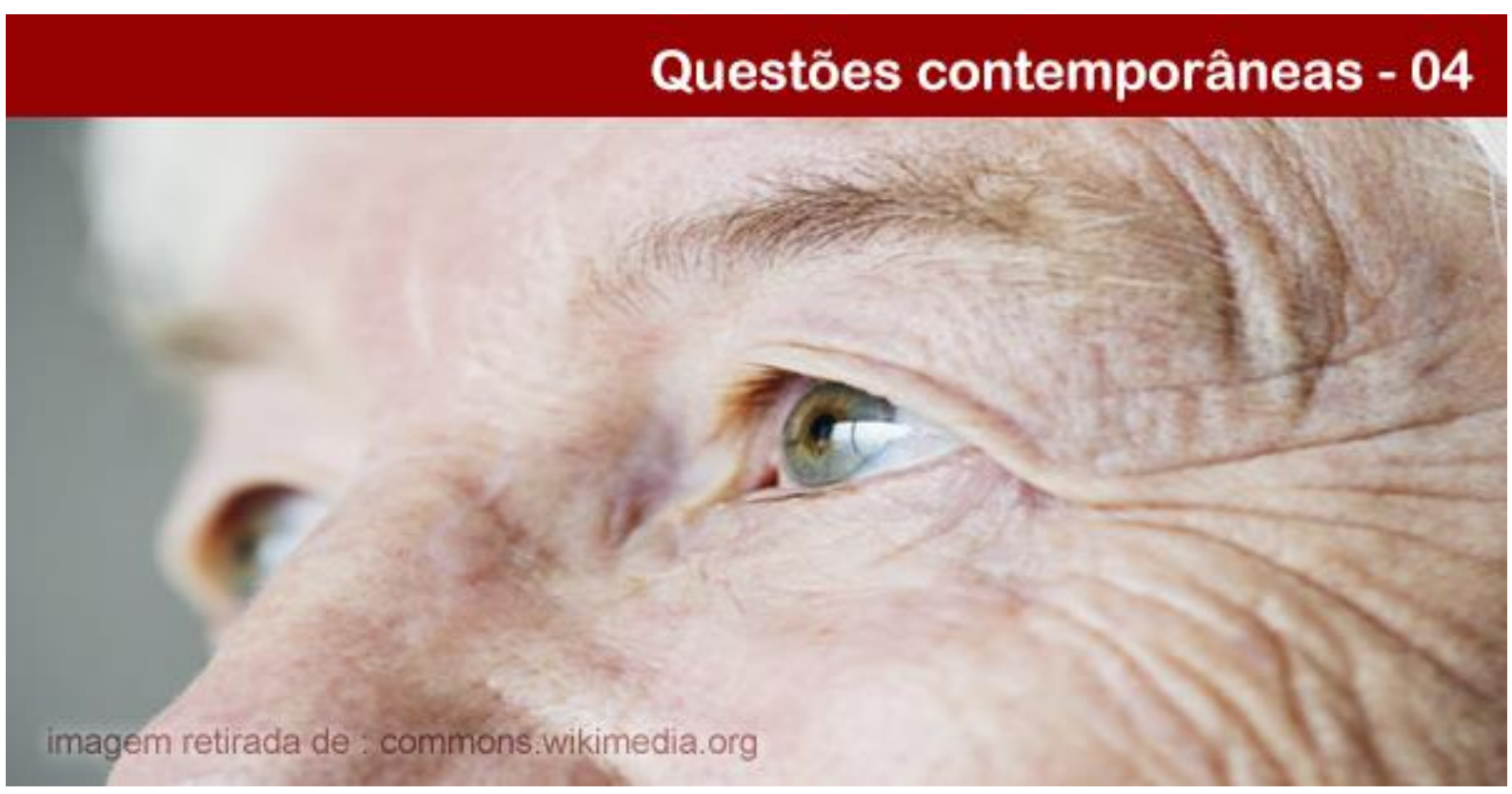

\title{
REFLEXÕES SOBRE A MORTE E A SENESCÊNCIA
}

\author{
Máximo Alessandro Mendes Ottoni \\ Professor das Faculdades Prisma de Montes Claros. Doutorando e Mestre em Desenvolvimento Social pela \\ Universidade Estadual de Montes Claros (Unimontes). Graduado em Serviço Social. E-mail: \\ maximo.ottoni@yahoo.com.br.
}

\section{Antônio Dimas Cardoso}

Professor titular de Sociologia na Universidade Estadual de Montes Claros (Unimontes). Doutor e Mestre em Sociologia pela Universidade de Brasília (UnB). Graduado em Ciências Sociais. E-mail: antonio.dimas@unimontes.br.

Resumo: O presente artigo tem por objetivo fomentar um debate acerca de temas polêmicos, que são pertinentes ao envelhecimento humano, mas que muitas vezes não são discutidos pela sociedade. Buscou-se, por meio de pesquisa bibliográfica, documental e de estudos empíricos, apresentar questões ligadas ao envelhecimento, à morte, à eutanásia e ao suicídio. Percebeu-se nesse estudo que, muitas vezes, alguns temas são considerados tabu, como é o caso da eutanásia, mas existem países como Holanda, Bélgica, Suíça e Colômbia em que esse procedimento já foi adotado e, em alguns casos, até mesmo regulamentado. Verificou-se neste trabalho que, muitas vezes, a morte não é o maior temor do ser humano, mas sim, o medo da perda da liberdade e do controle da sua própria vida. Apoio familiar, tratamento clínico e espiritualidade podem ser considerados grandes aliados na tentativa de se evitar o suicídio cometido por pessoas idosas.

Palavras-chave: Envelhecimento. Morte. Eutanásia. Suicídio.

\section{REFLECTIONS ON DEATH AND SENSE}

Abstract: The purpose of this article is to promote a debate about controversial issues there are pertinent to human ageing, but which are not often discussed by the society. Through bibliographic research, documentary and empirical studies, we presented questions related to ageing, death, euthanasia and suicide. It has been noted in this study that some topics are often considered a taboo, such as euthanasia, but there are countries such as the Netherlands, Belgium, Switzerland and Colombia where this procedure has already been adopted and, in some cases, even regulated. It has been found in this work that death is often not the greatest fear of the human being,

\section{POLÊM!CA $\mid$ LABORE (3:}

Polêmica - Revista Eletrônica da Uerj - Rua São Francisco Xavier, 524, $1^{\circ}$ andar bloco D, sl.1001 • Tels.: +55 21 2334-4088 / 4087 • http://www.e-publicacoes.uerj.br/index.php/polemica/index http://www.labore.uerj.br • laboreuerj@yahoo.com.br 
but rather the fear of loss of freedom and control of one's life. Family support, clinical treatments and spirituality can be considered to be great allies in trying to prevent suicide by older people.

Keywords: Aging. Death. Euthanasia. Suicide.

\section{Introdução}

O envelhecimento populacional é um fenômeno mundial. Avanços tecnológicos e melhoria nas condições de vida, em conjunto com a diminuição da natalidade, têm possibilitado o crescimento da população idosa. $\mathrm{O}$ desiderato de uma longa vida torna-se cada vez mais factível, consubstanciada pela ideia de bem-estar, de saúde e de boa forma. Representa a capacidade do indivíduo - inclusive o idoso - de absorver o que o mundo tem a oferecer em termos de experiências. O corpo fitness passa a ser uma premência da vida social moderna e, mais, uma condição para a longevidade.

Essa tendência mundial se constitui em um grande desafio no sentido de alcançar soluções para minimizar os efeitos negativos do envelhecimento no organismo humano. A busca pela longevidade se mostra promissora e, por consequência, também problemática, especialmente para aquele que já está situado na fase da chamada terceira idade. Na luta pela boa condição de vida, a senescência adquire centralidade social e atenção especial das políticas públicas para a pessoa idosa, no sentido de que essa fase da vida possa ser considerada a da melhor idade.

O isolamento dos idosos e a fase final de sua existência apresentam-se como questão social não mais circunscrita apenas a núcleos familiares, da intimidade do parentesco. Passam a ser tratados como uma problemática de interesse público, de luta por reconhecimento social. E isso requer, no dizer de Elias (2001, p. 9), uma "desmitologização da morte mais ampla do que temos hoje". Com o prolongamento da vida do ser humano, surgem novas questões a serem tratadas, e muitas delas polêmicas, como a morte, a eutanásia e o suicídio.

A morte, para muitos, pode ser algo considerado terrível, indesejável, embora inevitável; mas, para outros, que se encontram em situação fragilizada ou em estado terminal, o falecimento pode ser um alívio para acalentar a dor - a do moribundo e a de seus familiares e amigos. Elias (2001, p. 72) afirma que o "modo como uma pessoa morre" depende em boa medida de que ela tenha sido capaz de formular objetivos e alcançá-los, de imaginar tarefas e realizá-las durante a sua vida. A autor supõe que morrer é mais fácil para aqueles que acreditam terem feito a sua parte e mais difícil para os que sentem terem fracassado na busca de seus

\section{POLÊM!CA $\mid$ LABORE}

Polêmica - Revista Eletrônica da Uerj - Rua São Francisco Xavier, 524, $1^{\circ}$ andar bloco D, sl.1001 • Tels.: +55 21 2334-4088 / 4087 • http://www.e-publicacoes.uerj.br/index.php/polemica/index http://www.labore.uerj.br • laboreuerj@yahoo.com.br 
objetivos. Porém, “as razões desses sentimentos nem sempre são claras - essa também é uma área aberta à pesquisa" (ELIAS, 2001, p. 72).

Portanto, apesar de parecer ser um dos grandes temores da humanidade, a morte, pode ser vista pelos idosos de forma diferente. Ao invés de recearem a morte, os idosos muitas vezes a desejam, pois há ainda o medo maior, muitas vezes, de se tornarem dependentes de outras pessoas e perderem a sua liberdade e o controle de suas vidas.

Um falecimento mais assimilado, culturalmente, seria aquele que ocorre naturalmente, no qual o moribundo finda sua vida num leito, acolhido por familiares e amigos, recebendo palavras de conforto e reconhecimento por tudo que representou em vida (ELIAS, 2001). Porém, nem sempre é possível se ter um fim de vida dessa forma. Muitas vezes, a fragilidade do corpo e/ou a ausência de uma rede familiar desperta para outros discursos. Assim, o recurso da eutanásia poderia ser viável em casos de doenças incuráveis e debilitantes, como uma 'morte serena, sem sofrimento', já difundida, hoje, em países como a Suíça e a Holanda, onde há legalização da eutanásia, que pode ser feita a pedido do paciente ou da família. Para Lepargneur (1999), a eutanásia é uma forma de abreviar ou provocar a morte de uma pessoa, que tenha uma doença incurável, objetivando acabar com o seu sofrimento.

Nesse mesmo contexto, surge um outro fenômeno: o suicídio entre idosos, que será examinado a partir de causas multifatoriais e de difícil percepção, considerando sua maior probabilidade de ocorrência nessa faixa etária, em relação às outras fases da vida, devido às debilitações que o próprio envelhecimento proporciona às pessoas (SANTOS et al., 2017). Sousa et al. (2013) afirmam que, com o envelhecimento, alguns idosos podem apresentar quadros depressivos e isso ocasiona fragilidade mental, sendo um fator de risco para o suicídio. A maioria dos autores, inclusive clássicos da sociologia como Émile Durkheim e Maurice Halbwachs, reconhece que a causalidade do suicídio é complexa. Halbwachs (2002) sugere que o estudo do suicídio só pode ser aprofundado se o pesquisador estiver em condições de analisar os motivos do suicídio; enquanto Durkheim busca critérios de exterioridade para explicar o suicídio como sintoma de patologia e anomia na sociedade. Para Durkheim (2013), o suicídio não pode ser reduzido a um fenômeno psicológico ou psicopatológico, pois trata-se de um fato social $^{1}$, originário, portanto, socialmente.

\footnotetext{
${ }^{1} \mathrm{O}$ fato social para Durkheim são as forças que agem sobre o indivíduo, influenciando na maneira de agir, pensar e sentir e obrigando os indivíduos a se adaptar às regras da sociedade onde vivem (DURKHEIM, 1978).
}

\section{POLÊM!CA $\mid$ LABORE}

Polêmica - Revista Eletrônica da Uerj - Rua São Francisco Xavier, 524, $1^{\circ}$ andar bloco D, sl.1001 • Tels.: +55 21 2334-4088/4087 • http://www.e-publicacoes.uerj.br/index.php/polemica/index http://www.labore.uerj.br • laboreuerj@yahoo.com.br 
Este artigo, que se apoia principalmente nos conceitos de Norbert Elias, discute situações que podem ocorrer com determinados idosos, mas que ainda são consideradas um tabu na sociedade atual. Trata-se de um trabalho que procura pensar sociologicamente o problema social da morte e da senescência, incluindo reflexões sobre o suicídio e a eutanásia fatos e situações extremas que podem ocorrer com o envelhecimento. Portanto, busca-se discutir temas tidos por polêmicos, que também fazem parte do contexto senescente, mas que são pouco explorados pela literatura científica. Aborda questões que são parte da vida cotidiana, especialmente da pessoa idosa, no esforço de ampliar a compreensão sobre o fenômeno do envelhecimento e da morte, no contexto social. O artigo busca referências em fontes clássicas, como Durkheim, Halbwachs e, notadamente Elias, bem como utiliza dados técnicos e análises de pesquisadores contemporâneos e de instituições públicas.

\section{Breves considerações sobre o envelhecimento}

Como dito, o envelhecimento populacional é um fenômeno mundial, e sua tendência crescente foi detectada inicialmente nos países da Europa Ocidental no final do século XIX, depois nos países considerados desenvolvidos e, nas últimas décadas, centrou-se em países de desenvolvimento periférico, como é o caso do Brasil. Até 2060, conforme estimativa do Instituto Brasileiro de Geografia e Estatística - IBGE, o percentual de indivíduos acima de 65 anos passará dos atuais 9,2\% para 25,5\% (IBGE, 2018).

Uma das definições sobre envelhecimento foi estabelecida pela Organização Panamericana de Saúde - OPAS, como sendo

[...] um processo sequencial, individual, acumulativo, irreversível, não patológico, de deterioração de um organismo maduro, próprio a todos os membros de uma espécie de maneira que o tempo torne capaz de fazer frente ao estresse do meio-ambiente e, portanto, aumente sua possibilidade de morte (BRASIL, 2006, p. 08).

A morte seria uma realidade para todos os seres vivos que, mais cedo ou mais tarde, sentiriam os efeitos do envelhecimento nos seus corpos e, consequentemente, com a degeneração corporal, estariam mais próximos do findar da vida. Para que ocorra um envelhecimento 'digno', seria necessária uma proteção maior do Estado e da sociedade, mas percebe-se que, mesmo na contemporaneidade, muitos idosos encontram-se isolados. Elias relaciona o fenômeno do envelhecimento com a iminência da morte. E afirma que "os anos de decadência são penosos não só para os que sofrem, mas também para os que são deixados sós"

\section{POLÊM!CA $\mid$ LABORE}

Polêmica - Revista Eletrônica da Uerj - Rua São Francisco Xavier, 524, $1^{\circ}$ andar bloco D, sl.1001 • Tels.: +55 21 2334-4088 / 4087 • http://www.e-publicacoes.uerj.br/index.php/polemica/index http://www.labore.uerj.br • laboreuerj@yahoo.com.br 
(ELIAS, 2001, p. 8). Para o autor, o isolamento precoce do velho e do moribundo ocorre com mais frequência nas sociedades mais avançadas. Detecta, inclusive, que nessas sociedades passa existir o isolamento tácito ${ }^{2}$ dos idosos, em processo de senescência, da comunidade dos vivos, "saudáveis". Haveria, portanto, uma dificuldade de identificação de muitas pessoas com esse grupo. Daí a necessidade, cada vez mais crescente, de ações sociais e políticas públicas que possam, pelo menos, amenizar a "solidão dos moribundos" (ELIAS, 2001).

Com esse cenário, na atualidade, cresce o número de instituições em que as pessoas velhas, até então desconhecidas entre si, passam a viver juntas. Em contrapartida, aí, o envelhecimento geralmente é acompanhado pelo esgarçamento dos laços sociais, que ultrapassam o círculo familiar mais estreito. Apesar disso, nessa etapa da existência humana, inexoravelmente, permanece uma ideia: a morte como realidade iminente, numa perspectiva imediata de acaso da vida. A condição corporal - e muitas vezes a mental - entra em sua fase moribunda de vida, persistindo a associação com o isolamento emocional. "Muito asilos são, portanto, desertos de solidão" (ELIAS, 2001, p. 86).

A determinação da idade para o idoso é relativa ao tempo e ao lugar, pois além dos fatores pessoais e culturais, o próprio aumento da expectativa de vida coloca em discussão essa tentativa de definir um padrão etário. Diamond (2014) afirma que, em determinadas regiões, onde a expectativa de vida é baixa, uma pessoa com 50 anos é considerada uma anciã. É o caso da Nova Guiné, em que a expectativa de vida é abaixo dos quarenta anos. Seria quase inimaginável um cidadão desse país pensar que um homem pudesse ultrapassar os 100 anos de idade, fato que já é realidade em diversos países, especialmente nos considerados desenvolvidos.

No Brasil, a Política Nacional do Idoso estabelece o parâmetro etário para pessoas idosas, segundo o qual são os indivíduos com idade igual ou superior a 60 anos (BRASIL, 1994). A Organização Mundial da Saúde (OMS) considera idosa a pessoa com 60 anos ou mais, para aqueles que residam em países em desenvolvimento, e 65 anos ou mais, para os residentes dos países desenvolvidos (CAMARANO, 2004). No entanto, Diamond (2014) discorda dessa “definição universal”, pois a questão do envelhecimento irá depender da sociedade em que a

\footnotetext{
${ }^{2}$ Para Elias (2001), o isolamento tácito seria de difícil percepção, pois envolve um esfriamento das relações sociais dos idosos para com pessoas próximas e uma separação em relação aos demais membros da sociedade.
}

\section{POLÊM!CA | LABORË.}

Polêmica - Revista Eletrônica da Uerj - Rua São Francisco Xavier, 524, $1^{\circ}$ andar bloco D, sl.1001 • Tels.: +55 21 2334-4088 / 4087 • http://www.e-publicacoes.uerj.br/index.php/polemica/index http://www.labore.uerj.br • laboreuerj@yahoo.com.br 
pessoa está inserida e também da perspectiva pessoal. Nesse contexto, o autor faz um relato pessoal:

\begin{abstract}
Na minha adolescência, eu considerava as pessoas de vinte e tantos anos como aparentemente no auge da vida e da sabedoria, pessoas de trinta anos como de meiaidade e qualquer um a partir dos sessenta como velho. Agora que tenho 75 anos, considero meus sessenta anos e o início dos meus setenta como o auge da minha vida, e penso que a velhice talvez comece por volta dos 85 ou 90, dependendo da minha saúde. (DIAMOND, 2014, p. 225).
\end{abstract}

A partir de afirmações como a de Diamond (2014), pode-se verificar que o envelhecer está relacionado à percepção de uma pessoa em relação à outra, e também à cultura a qual essa pessoa pertença. Além disso, a esperança de vida pode ter uma grande variação, se comparadas localidades diferentes. Kliksberg (2000) em uma pesquisa, realizada em 1997, comparou 26 países mais ricos do mundo com os 49 países mais pobres e percebeu que a esperança de vida dos países mais ricos foi de 25 anos a mais.

É consenso, entretanto, a necessidade de aprofundamento de saber nessa área. No Brasil, o conhecimento da sociedade em relação aos aspectos do envelhecimento e da morte aumentou substancialmente nas últimas décadas; tornou-se mais bem fundamentado, pelo menos estatisticamente. Em tese, a capacidade de controle institucional aumentou com essa expansão, principalmente com o surgimento de programas e ações de atenção ao idoso, notadamente na Saúde Pública. Dados oficiais mostram o crescimento da população idosa, o que acaba por exigir reconhecimento e implementação de política sociais voltadas à essa população.

No Gráfico 01 pode-se perceber, tanto o crescimento dessa população senil ${ }^{3}$, quanto o prolongamento da vida entre os anos de 1940 a 2000.

No sentido relativo a velhice.

\title{
POLÊM!CA $\mid$ LABORE
}

Polêmica - Revista Eletrônica da Uerj - Rua São Francisco Xavier, 524, $1^{\circ}$ andar bloco D, sl.1001 • Tels.: +55 21 2334-4088 / 4087 • http://www.e-publicacoes.uerj.br/index.php/polemica/index http://www.labore.uerj.br • laboreuerj@yahoo.com.br 
Gráfico - 1: População idosa brasileira - 1940-2000

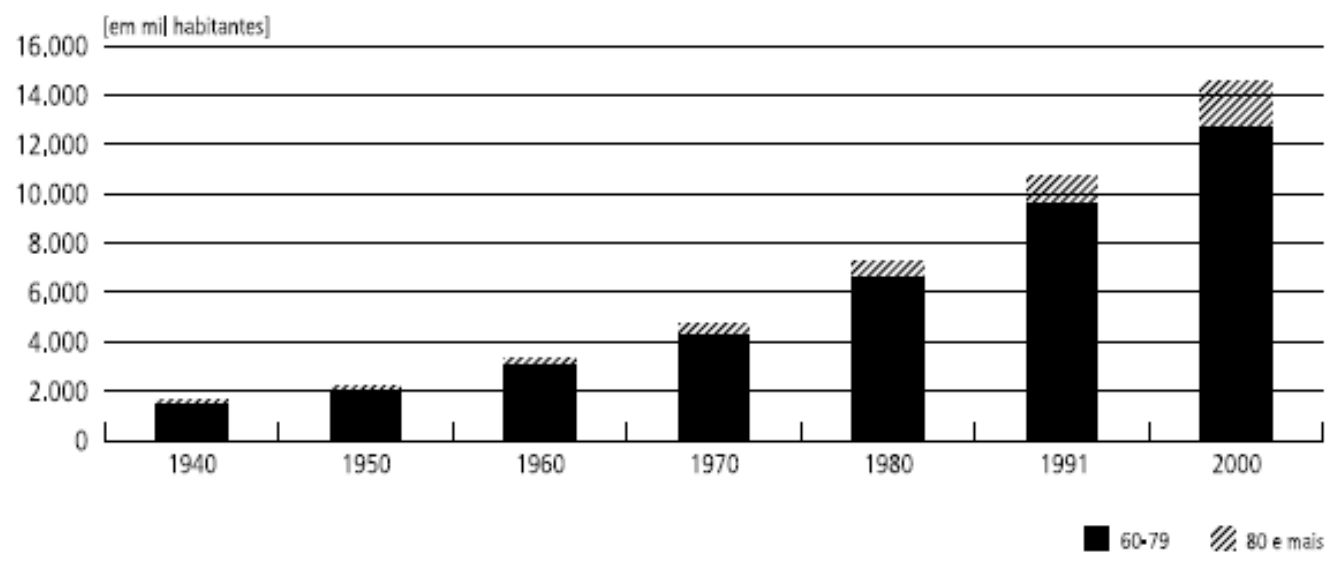

Fonte: Camarano, 2004.

Verifica-se no Gráfico 01, além do aumento do número de idosos demonstrados nas sete décadas e, por conseguinte da expectativa de vida, um aumento da população com 80 anos ou mais, dado significativo da maior longevidade do idoso brasileiro nas décadas explicitadas.

\section{A cultura da morte}

O findar da vida sempre foi algo que intrigou a humanidade em diversos momentos da história. Na mitologia, uma das formas mais antigas de se encarar a morte era a ideia de uma outra vida, podendo ela ser no Hades ${ }^{4}$ ou no Valhalla ${ }^{5}$, no Inferno ou no Paraíso (ELIAS, 2001).

Contudo, não se sabe ao certo para onde as pessoas vão (ou se vão) após a sua morte, mas muitas creem em algo além da vida. A religião seria uma forma de tentar explicar essa questão, e também uma maneira de acalentar a perda. Diamond (2014) afirma que

Praticamente todas as sociedades humanas conhecidas têm "religião", ou algo parecido. Isso sugere que a religião preenche alguma necessidade humana universal ou, pelo menos, brota de alguma parte da natureza humana que é comum a todos nós (DIAMOND, 2014, p. 314).

Além da religião, a cultura que envolve o ato fúnebre também seria uma forma de amenizar a perda de uma pessoa. Na Idade Média, Elias (2001) argumenta que o tema morte era presente nas conversas, nas artes e na literatura, principalmente com a peste negra, que

4 De acordo com a mitologia grega, seria o deus do submundo e dos infernos. Disponível em: https://www.significados.com.br/mitologia-grega/. Acesso em: 02 out. 2018.

${ }^{5}$ Segundo a mitologia escandinava, seria uma espécie de habitação dos heróis mortos em combate. Disponível em: https://www.dicio.com.br/valhala/. Acesso em: 03 out. 2018.

\section{POLÊM!CA $\mid$ LABORE}

Polêmica - Revista Eletrônica da Uerj - Rua São Francisco Xavier, 524, $1^{\circ}$ andar bloco D, sl.1001 • Tels.: +55 21 2334-4088 / 4087 • http://www.e-publicacoes.uerj.br/index.php/polemica/index http://www.labore.uerj.br • laboreuerj@yahoo.com.br 
gerou grande temor e milhares de mortes. Havia o medo e apreensão em torno dessa temática, e isso era amplamente difundido pela Igreja Católica, que pregava o paraíso para os seguidores da doutrina cristã e, para os hereges, o inferno seria o destino.

No pré-capitalismo, quando uma pessoa morria, era velada em casa pelos familiares e amigos, podendo ter a companhia de uma autoridade religiosa (ARAÚJO, 2012). Mas, na atualidade, o morrer passou a ser mais solitário, pois morre-se em um hospital, cercado por médicos, enfermeiros e aparelhos. Isso implica num afastamento dos vivos em relação aos moribundos a ponto de que uma pessoa não consiga se expressar com palavras de consolo para um parente do falecido. Elias (2001, p. 10) afirma que "na verdade não é a morte, mas o conhecimento da morte que cria problemas para os seres humanos”. Portanto, a morte é um problema dos vivos.

Araújo (2012) diz que a morte, na contemporaneidade, foi incorporada pela sociedade de consumo e se tornou um negócio, em especial para as empresas funerárias, e que as pessoas associam um funeral mais "completo", como uma forma de aliviar o fardo da família. Essa ilusão casa bem com os interesses comerciais que se ligam à morte, podendo as empresas obter grande lucro com os serviços prestados, como os atos de lavar, embalsamar, maquiar, arrumar o corpo, dentre outros.

O autor diz ainda que já existe um atendimento mais humanizado para clientes vip. São cerimônias de luxo, com música, coquetéis, transmissão online da cerimônia, sala de descanso, refeições para os presentes, limusines para o trajeto até o cemitério e tudo para deixar a família fora dos preparativos fúnebres, e para dar uma aparência de que o morto está vivo. Existem também caixões personalizados com aquilo que o falecido gostava, e até a opção de transformar as cinzas dos cremados em diamante e em outros objetos.

\section{Novas percepções em relação à morte}

Elias (2001) comenta que, no passado, a morte era mais pública, pois as pessoas estavam mais próximas, mais sociáveis e, com isso, podiam se solidarizar melhor uns com os outros. No século XVII, havia poemas fúnebres e o tema era mais comum. Falava-se em corpos em decomposição, sepultura, enterro, sem a censura atual, e o assunto era comentado, inclusive com as crianças. No século XXI, se exclui tanto o tema morte como o ser que se encontra

\section{POLÊM!CA $\mid$ LABORE}

Polêmica - Revista Eletrônica da Uerj - Rua São Francisco Xavier, 524, $1^{\circ}$ andar bloco D, sl.1001 • Tels.: +55 21 2334-4088 / 4087 • http://www.e-publicacoes.uerj.br/index.php/polemica/index http://www.labore.uerj.br • laboreuerj@yahoo.com.br 
moribundo do meio social. Comenta-se que os "vivos" nem sequer sabem o que conversar com alguém próximo à morte.

Segundo o autor (2001), o distanciamento que se faz em torno da morte e do ser "moribundo" é tão grande, que a família, muitas vezes, não consegue se manter próxima e nem se despedir de um ente querido. A sensação dos familiares, no momento, é de impotência. Isso também vale para os sentimentos em relação à morte, pois eles são reprimidos subjetivamente na modernidade. Muitas vezes as crianças não são comunicadas da morte de um familiar, pelo temor das mesmas ficarem "traumatizadas"; o anúncio da morte de um conhecido é escondido de um idoso, temendo que ele sofra ou venha a apresentar algum problema de saúde devido à notícia do falecimento; ou mesmo uma doença grave é ocultada dos demais por algum temor, ou porque a pessoa não quer que os outros a vejam fragilizada. "No século XVII, os homens podiam chorar em público; isso se tornou hoje difícil e pouco frequente. Só as mulheres ainda são capazes, socialmente livres para fazê-lo - por quanto tempo ainda?" (ELIAS, 2001, p. 35).

Em relação ao ato de morrer, Ribeiro et al. (2017) verificaram estudos sobre envelhecimento e perceberam que, em nível mundial, o maior temor dos idosos não é a morte em si, e sim, o fato de se tornarem dependentes de outras pessoas devido às suas próprias limitações físicas, e isso está ligado diretamente à perda da liberdade e do controle da própria vida. Quando isso ocorre, o idoso tem maior propensão de desejar a morte, podendo culminar em práticas como a eutanásia ou até mesmo o suicídio.

\section{Morte por eutanásia}

Para Lepargneur (1999), a eutanásia seria a utilização de recursos capazes de apressar ou provocar a morte de uma pessoa com doença incurável, com o intuito de finalizar o seu sofrimento. Diniz e Costa (2004) afirmam que já é latente o discurso da morte por eutanásia, fomentados pela bioética e pelo avanço da biomedicina, em que se discute o direito de escolher ou não o momento da morte. Mas esse discurso encontra diversos entraves de ordem técnica e ética, em especial pelos profissionais de saúde, que são treinados para salvar vidas.

No mundo, a Holanda e a Colômbia são exemplos de alguns países que, de algum modo, regulamentaram uma forma de eutanásia. A Holanda foi o primeiro país a legalizá-la, em 1993,

\section{POLÊM!CA $\mid$ LABORE}


e a Colômbia permitiu a eutanásia passiva ${ }^{6}$ a partir de 1997 (DINIZ; GUILHEM, 2002). Porém, para que possa acontecer a eutanásia, é necessário diagnosticar a não possibilidade de cura de um tratamento perante uma doença grave por meio de uma equipe multidisciplinar de saúde (SINGER, 2002).

No Brasil, a eutanásia sofre forte resistência social. Pela lei, é considerada crime de homicídio, podendo gerar penalidades. No geral, não se aceita que alguém, notadamente o médico, provoque deliberadamente a morte de alguém. Diniz e Costa (2004) afirmam que no país existem raros debates públicos sobre a eutanásia, ainda que existam casos dentro da temática, como o projeto de lei no estado de São Paulo que prevê a recusa de paciente para tratamentos dolorosos, que prolonguem a vida.

\begin{abstract}
Na verdade, em algumas situações críticas e terminais, em face da inevitabilidade da morte e do esgotamento das alternativas curativas ou paliativas biomédicas, a possibilidade de decidir sobre a própria morte assume um papel de conforto moral. Um número crescente de pessoas, especialmente idosas, procura auxílio de médicos e enfermeiras não apenas para tratar doenças, mas para garantir que a experiência da morte seja também resultado de escolhas individuais (DINIZ; COSTA, 2004, p. 123).
\end{abstract}

Diniz e Costa (2004) narram uma história supostamente verídica, publicada anonimamente, no respeitado periódico médico, o Journal of American Medical Association (Jama), publicado em 1988. Na história, um médico residente se vê diante de uma jovem de nome Debbie, em estado terminal, diagnosticada com câncer, e que pedia para que o médico acabasse com o seu sofrimento. O médico procedeu conforme o pedido da jovem e injetou uma dose excessiva de medicamento que a matou. A partir desse relato, houve diversas discussões bioéticas e polêmicas sobre o assunto. Para muitos profissionais, a história de Debbie, publicada no Jama, pode ser considerada um assassinato e foi caso de investigação policial. Se foi verídica ou não, essa história serviu para adoção de procedimentos em pelo menos quatro países da Europa Ocidental (Holanda, Bélgica, Luxemburgo e Suíça) para a prática assistencial da eutanásia, chamada também de "morte assistida".

Um caso emblemático no campo foi o de Sigmund Freud que, após 32 cirurgias na garganta devido a um câncer, ficou em estado delicado de saúde e solicitou sempre a verdade de seu médico, pedindo que não o deixasse sofrer inutilmente. Após anos de tratamento e vários desconfortos, como cheiro fétido na garganta devido à lesão e estado caquético do corpo, Freud

\footnotetext{
${ }^{6}$ A eutanásia passiva ou ortotanásia seria o não prolongamento da vida de uma pessoa que se encontra em estado terminal, mediante a suspensão do tratamento de uma doença considerada incurável (RASTELLI, 2017).
}

\title{
POLÊM!CA $\mid$ LABORE
}

Polêmica - Revista Eletrônica da Uerj - Rua São Francisco Xavier, 524, $1^{\circ}$ andar

bloco D, sl.1001 • Tels.: +55 21 2334-4088 / 4087 • http://www.e-publicacoes.uerj.br/index.php/polemica/index

http://www.labore.uerj.br • laboreuerj@yahoo.com.br 
solicitou a eutanásia ao seu médico e este o fez, aplicando duas injeções de morfina (SANTOS, 2003).

Um caso de muita repercussão na mídia, no Brasil, mostrou o drama do jornalistaapresentador de TV, Marcelo Rezende. Diagnosticado com câncer no pâncreas, com metástase no fígado, o enfermo recebeu a informação de que a quimioterapia daria uma sobrevida a ele de até três anos, mas não o curaria. Após uma sessão dolorosa e efeitos colaterais, o apresentador optou por deixar o tratamento, se apegando a fé e a tratamentos alternativos, vindo a falecer em 16/09/2017, em São Paulo (BERGAMASCO; KUSUMOTO, 2017).

Percebe-se que nos dois últimos casos apresentados a eutanásia foi realizada, mas de diferentes formas. O primeiro, após muitas tentativas de tratamento, optou por um tipo de eutanásia voluntária. O segundo, rejeitou os tratamentos modernos da medicina, falecendo sob cuidados paliativos. Diniz e Costa (2004) comentam diversos estudos em que centros de terapia intensiva apontam para a prática de eutanásia passiva, que é o desligamento dos aparelhos, em pacientes infantis ou adultos. Também existem situações cuja pessoa é deixada morrer livremente, sem intervenções tecnológicas ou hospitalares, mas esses temas são sigilosos e evitados por muitos profissionais.

\section{$\underline{\text { Suicídio cometido por idosos }}$}

Dependência e limitação física, conforme já foi dito, podem ser fatores preponderantes para o estímulo ao suicídio cometido por idosos. Embora trate da questão de forma geral, incluindo diversas categorias sociais, Durkheim (2013) enfatiza as implicações do egoísmo para o crescimento do suicídio, que ele considera como fato social. De acordo com o autor, o egoísmo é provocado pelo individualismo excessivo, sendo mais frequente nas profissões características das sociedades industriais modernas, em período de boom econômico, do que nas sociedades tradicionais.

Halbwachs (2002), examinando posteriormente a teoria de Durkheim, reconhece a influência dos fenômenos patológicos, mas sugere a busca de motivos para compreensão do suicídio. Para Halbwachs, ao contrário de Durkheim, o suicídio deve ser interpretado como uma solução estratégica dada pelo indivíduo a problemas existenciais. Esses dois autores clássicos trabalharam com dados estatísticos, mas claramente direcionaram suas investigações aos

\section{POLÊM!CA $\mid$ LABORE}

Polêmica - Revista Eletrônica da Uerj - Rua São Francisco Xavier, 524, $1^{\circ}$ andar bloco D, sl.1001 • Tels.: +55 21 2334-4088 / 4087 • http://www.e-publicacoes.uerj.br/index.php/polemica/index http://www.labore.uerj.br • laboreuerj@yahoo.com.br 
estratos profissionais das populações europeias, estabelecendo correlação com os indicadores de anomia $^{7}$.

Sousa et al. (2013) dizem que o suicídio é um autoaniquilamento cometido por alguém em situação vulnerável, com a finalidade de acabar com uma dor psicológica insuportável. Atualmente, o suicídio cometido por idosos se tornou um problema de saúde pública, pois com o envelhecimento, a fragilidade da saúde pode ocasionar no comprometimento da saúde mental e, consequentemente, levar a quadros depressivos, a ter pensamentos suicidas ou até mesmo a cometer o autoextermínio.

Os idosos no contexto social e cultural, em determinadas fases de vida - como aposentadoria, impossibilidade de exercer a profissão por dependências físicas e psicológicas e surgimento de doenças crônicas - se deparam com mudanças negativas e perdas que, frequentemente, lhes causam uma espécie de morte social e subjetiva (SOUSA et al., 2013, p. 5).

Ribeiro et al. (2017) colocam outras perdas que se tornam impactantes para os idosos, como a perda de entes queridos, em especial o cônjuge, visto que a viuvez trará grandes impactos para a pessoa, como a solidão. Outro fator é a aposentadoria, em especial a compulsória, pois haverá um sentimento de inutilidade para a pessoa, além do afastamento dos colegas de trabalho e da redução financeira.

Sobre a solidão, Félix (2018) disserta sobre a criação do Ministério da Solidão pelo Reino Unido, dizendo que o problema de pessoas idosas ficarem sozinhas é maior do que a depressão, suicídio ou mortes por queda, pois a taxa de longevidade dos britânicos começou a decrescer. A justificativa foi que as reformas neoliberais, como previdência, privatizações, flexibilização trabalhista e diminuição da proteção social realizadas por Margareth Thatcher há quatro décadas, contribuíram para essa redução.

No suicídio cometido por idosos, Santos et al. (2017) dizem que esse é um tema complexo e que não existe um único fator para que ele ocorra, mas sim, causas multifatoriais, como os fatores sociais, psicológicos e culturais. Os autores explicam que o suicídio em idosos é, em geral, de difícil percepção, é mais fácil de acontecer se comparado a outros estágios da vida e pode ocorrer de diversas formas, até mesmo por inanição.

\footnotetext{
${ }^{7}$ Anomia seria algo que não possui norma, lei ou regras. Seria parecido com uma anarquia ou uma desorganização. Disponível em: https://www.dicio.com.br/anomia/. Acesso em: 03 out. 2018.

\section{POLÊM!CA $\mid$ LABORE}

Polêmica - Revista Eletrônica da Uerj - Rua São Francisco Xavier, 524, $1^{\circ}$ andar bloco D, sl.1001 • Tels.: +55 21 2334-4088 / 4087 • http://www.e-publicacoes.uerj.br/index.php/polemica/index http://www.labore.uerj.br • laboreuerj@yahoo.com.br
} 
Sousa et al. (2013) fizeram uma investigação sobre o suicídio de idosos em três cidades do Nordeste brasileiro, e perceberam algumas causas; uma delas foi a migração do campo para a cidade, em que a ruptura de laços sociais, a perda de vínculos, de cultura e a dificuldade de adaptação ao estilo urbano contribuíram para o agravamento da vulnerabilidade.

Ribeiro et al. (2017) comentam um estudo com 30 idosos na Holanda, no qual foi pesquisado o desejo de morte. Como resultado, a maioria dos entrevistados apresentou desejo moderado a forte sobre o desejo de morrer. Os idosos relataram que as perdas, como a do(a) companheiro(a) e da independência, foram cruciais para a perda do sentido da vida. Entretanto, um outro estudo com idosos na China demonstrou que, mesmo com as adversidades, os idosos buscam viver uma vida normal, e também buscam conforto na espiritualidade. A espiritualidade também foi relatada em outros estudos, no qual os idosos aceitaram a sua condição e apesar de sentirem o desejo de morrer, não o faziam por acharem que deveriam esperar a vontade de Deus.

Sousa et al. (2013) dizem que o suicídio ainda é tratado como tabu pela sociedade e por isso as pessoas não conversam sobre o tema. Isso pode ser considerado como uma forma de "recalcamento" tanto no plano individual como no social, na qual a família torna o fato algo restrito e até sigiloso. Quando o suicídio ocorre com o idoso, o recorrente é pensar que 'o idoso que perdeu a sua vontade de viver' ou 'quer é ser ouvido'. Possivelmente, o apoio da família seria um fator fundamental para que se possa evitar o suicídio nesse segmento da população, além dos tratamentos clínicos, psicológicos e de uma equipe multiprofissional, que seriam necessários ao acompanhamento da pessoa senescente.

\section{Considerações finais}

Foi percebido neste estudo que o envelhecimento pode ser visto de diversas formas, e isso dependerá da percepção pessoal, da época analisada e também da localidade onde o cidadão habita, e não somente das definições oficiais dos órgãos nacionais e internacionais.

Em relação à morte, verificou-se que a decadência das pessoas, a que denominamos de envelhecimento e morte, coloca para a sociedade contemporânea certo número de tarefas e desafios, principalmente no enfrentamento ao problema da solidão e isolamento do idoso - uma tendência das sociedades contemporâneas. $\mathrm{O}$ ato de morrer passou a ser mais solitário. Atualmente, morre-se em companhia de profissionais de saúde e maquinários hospitalares. O

\section{POLÊM!CA $\mid$ LABORE}

Polêmica - Revista Eletrônica da Uerj - Rua São Francisco Xavier, 524, $1^{\circ}$ andar bloco D, sl.1001 • Tels.: +55 21 2334-4088 / 4087 • http://www.e-publicacoes.uerj.br/index.php/polemica/index http://www.labore.uerj.br • laboreuerj@yahoo.com.br 
velório, fica a cargo de empresas funerárias, podendo até mesmo vir a ser um grande evento festivo; o que dependerá da vontade e das condições socioeconômicas de parentes e amigos do falecido.

Para os que permanecem, as exigências do fitness do corpo, num esforço moderno de prolongamento da vida saudável, possivelmente não são os únicos fatores que contribuem para o isolamento dos idosos em nossos dias. Os planejamentos governamentais e os planos privados de saúde, de atenção à pessoa idosa, funcionam conforme uma lógica de balanços de custos e benefício econômico, o que torna a vida ainda mais onerosa para aqueles em situação de senescência. As instituições, públicas e privadas, muitas vezes se desobrigam de responsabilidades, no que diz respeito a atenção integral à população idosa, tratando das demandas públicas por meio de ações focais, localizadas, quando muito.

Dentre as formas de morrer, a eutanásia, proibida na maioria dos países, começa a ser uma realidade em determinadas sociedades, mesmo que de formas variadas. Para que ocorra a eutanásia, é necessário que a pessoa seja portadora de uma doença incurável e tenha o aval de uma equipe multidisciplinar de saúde. Outra possibilidade considerada é o suicídio cometido por idosos, uma vez que muitos tomam essa atitude devido a quadros depressivos, perdas do companheiro e de familiares, sensação de impotência para exercer atividades laborais, solidão e diversos outros fatores. Percebe-se que o suicídio em idosos é de difícil percepção e é mais cometido se comparado ao suicídio em outros estágios da vida. Algumas das formas de se tentar evitar o suicídio entre idosos seriam a espiritualidade, os tratamentos clínicos e o apoio familiar.

Este artigo procurou problematizar questões que são cruciais para a compreensão do envelhecimento populacional, para além dos dados estatísticos sobre o fenômeno. Apoiando-se em autores fundamentais como Norbert Elias e no debate contemporâneo, buscou-se identificar nas atitudes extremas de finitude de uma vida, como a prática do suicídio e a eutanásia, elementos constitutivos da transitoriedade pessoal, face à expectativa de vida maior. Isso se reflete mais decisivamente na figura do idoso. A atitude em relação à morte e a imagem da morte nas sociedades contemporâneas não podem ser tratadas como fenômenos corriqueiros, considerando que, como afirma Elias, "ficou mais fácil esquecer a morte no curso normal da vida" (ELIAS, 2001, p. 15).

Tudo isso ocorre de forma acelerada, o que se constitui em grande desafio na contemporaneidade. O declínio físico apresenta-se como uma das principais características do

\section{POLÊM!CA $\mid$ LABORE}

Polêmica - Revista Eletrônica da Uerj - Rua São Francisco Xavier, 524, $1^{\circ}$ andar bloco D, sl.1001 • Tels.: +55 21 2334-4088 / 4087 • http://www.e-publicacoes.uerj.br/index.php/polemica/index http://www.labore.uerj.br • laboreuerj@yahoo.com.br 
envelhecimento populacional. No entanto, as alterações que envolvem o processo de senescência não dizem respeito a doenças, mas sim resultado de mudanças orgânicas, funcionais e psicológicas. Sendo assim, o que se busca é a equidade na saúde, com destaque para a pessoa idosa. A equidade na saúde deve levar em consideração a maneira como a alocação de recursos e os arranjos sociais ligam a saúde a outros aspectos da organização da sociedade. Assim, nenhum grupo deve ser discriminado. $\mathrm{O}$ mundo contemporâneo exige capacidade de obtenção de boa saúde. E isso vale também para os idosos em processo de finitude da vida.

\section{Referências}

ARAÚJO, R. B. A mercantilização da morte na sociedade de consumo. Revista Habitus, Goiânia, v. 10, n. 2, p. 341-353, jul./dez. 2012. Disponível em: http://seer.pucgoias.edu.br/index.php/habitus/article/view/2836/1731. Acesso em: 02 out. 2018.

BERGAMASCO, D.; KUSUMOTO, M. Marcelo Rezende: a opção pelo tratamento alternativo. Revista VEJA, 22 set. 2017. Disponível em: https://veja.abril.com.br/revista-veja/a-escolha-de-rezende/. Acesso em: 08 jan. 2018.

BRASIL. Casa Civil. Subchefia para Assuntos Jurídicos. Política Nacional do Idoso. Lei no 8.842, de 4 de janeiro de 1994. Dispõe sobre a Política Nacional do Idoso, cria o Conselho Nacional do Idoso e dá outras providências. Diário Oficial União, Brasília, DF, 5 jan. 1994. Disponível em: http://www.planalto.gov.br/ccivil_03/leis/18842.htm. Acesso em: 01 out. 2018.

Ministério da Saúde. Secretaria de Atenção à Saúde. Departamento de Atenção Básica. Envelhecimento e saúde da pessoa idosa. Brasília, DF: Ministério da Saúde, 2006. (Cadernos de Atenção Básica n ${ }^{\circ} 19$, Série A, Normas e Manuais Técnicos).

CAMARANO, A. A. (Org.). Os novos idosos brasileiros: muito além dos 60? Rio de Janeiro: IPEA, 2004.

DIAMOND, J. O mundo até ontem: o que podemos aprender com as sociedades tradicionais? Rio de Janeiro: Record, 2014.

DINIZ, D.; COSTA, S. Morrer com dignidade: um direito fundamental. In: CAMARANO, A. A. (Org.). Os novos idosos brasileiros: muito além dos 60? Rio de Janeiro: IPEA, 2004. p. 121-134.

DINIZ, D.; GUILHEM, D. A teoria principialista. O que é bioética? São Paulo: Brasiliense, 2002. p. 34-38.

DURKHEIM, É. As regras do método sociológico. São Paulo: Abril, 1978.

O suicídio: estudo de sociologia. São Paulo: Editora WMF Martins Fontes, 2013.

ELIAS, N. A solidão dos moribundos seguida de envelhecer e morrer. Rio de Janeiro: Jorge Zahar, 2001.

FÉLIX, J. Por que Theresa May Criou o Ministério da Solidão. Portal do Envelhecimento, 21 jan. 2018. Disponível em: http://www.portaldoenvelhecimento.com.br/por-que-theresa-may-criou-o-ministerio-da-solidao/. Acesso em: 28 jan. 2018.

\section{POLÊM!CA $\mid$ LABORE}

Polêmica - Revista Eletrônica da Uerj - Rua São Francisco Xavier, 524, $1^{\circ}$ andar bloco D, sl.1001 • Tels.: +55 21 2334-4088 / 4087 • http://www.e-publicacoes.uerj.br/index.php/polemica/index http://www.labore.uerj.br • laboreuerj@yahoo.com.br 
HALBWACHS, M. Les causes du suicide (Broché). Paris: Presses Universiteres de France, 2002.

IBGE - INSTITUTO BRASILEIRO DE GEOGRAFIA E ESTATÍSTICA. Projeção da população do Brasil e das Unidades da Federação. 2018. Disponível em: https://www.ibge.gov.br/apps/populacao/projecao/. Acesso em: 25 jun. 2018.

KLIKSBERG, B. Desigualdade na América Latina: o debate adiado. São Paulo: Cortez, Brasília: UNESCO, 2000.

LEPARGNEUR, H. Bioética da eutanásia: argumentos éticos em torno da eutanásia. Revista Bioética, v. 7, p. 41-48, 1999. Disponível em: http://revistabioetica.cfm.org.br/index.php/revista_bioetica/article/view/292.

Acesso em: 10 jan. 2018.

RASTELLI, B. Eutanásia passiva: uma análise jurídico-social. 2017. Disponível em:

https://rastellicbarbara.jusbrasil.com.br/artigos/454179758/eutanasia-passiva. Acesso em: 10 set. 2018.

RIBEIRO, M. dos S.; BORGES, M. da S.; ARAÚJO, T. C. C. F. de; SOUZA, M. C. dos S. Estratégias de enfrentamento de idosos frente ao envelhecimento e à morte: revisão integrativa. Revista Brasileira de Geriatria e Gerontologia, Rio de Janeiro, v. 20, n. 6, p. 880-888, nov./dez. 2017.

SANTOS, E. G. de O.; OLIVEIRA, Y. O. M. da C.; AZEVEDO, U. N. de; NUNES, A. D. da S.; AMADOR, A. E.; BARBOSA, I. R. Análise espaço-temporal da mortalidade por suicídio em idosos no Brasil. Revista Brasileira de Geriatria e Gerontologia, Rio de Janeiro, v. 20, n. 6, p. 854-865, nov./dez. 2017.

SANTOS, L. F. Eutanásia: Para Poder Amar a Vida até ao Fim. Interações: Sociedade e as novas modernidades, n. 4, abr. 2003. Disponível em: http://www.interacoes-ismt.com.index.php/revista/article/view/66. Acesso em: 8 jan. 2018.

SIGNIFICADO de anomia. Dicionário on line de Português. Disponível em: https://www.dicio.com.br/anomia/. Acesso em: 03 out. 2018.

SIGNIFICADO da mitologia grega. Significados. Disponível em: https://www.significados.com.br/mitologiagrega/. Acesso em: 02 out. 2018.

SIGNIFICADO de valhala. Dicionário on line de Português. Disponível em: https://www.dicio.com.br/valhala/. Acesso em: 03 out. 2018.

SINGER, P. Justificando a eutanásia voluntária. Vida ética. Rio de Janeiro: Ediouro, 2002. p. 242-250.

SOUSA, G. de S.; SILVA, R. M. da; FIGUEIREDO, A. E. B.; MINAYO, M. C. de S.; VIEIRA, L. J. E. de S. Circunstâncias que envolvem o suicídio de pessoas idosas. Interface, Botucatu [online], v. 18, n. 49, p. 389-402, mar. 2013. Disponível em: http://www.scielo.br/pdf/icse/v18n49/1807-5762-icse-1807-576220130241.pdf. Acesso em: 18 jan. 2018.

Recebido em: 16/10/2018.

Aceito em: 30/03/2019.

\section{POLÊM!CA | LABORE}

Polêmica - Revista Eletrônica da Uerj - Rua São Francisco Xavier, 524, $1^{\circ}$ andar bloco D, sl.1001 • Tels.: +55 21 2334-4088 / 4087 • http://www.e-publicacoes.uerj.br/index.php/polemica/index http://www.labore.uerj.br • laboreuerj@yahoo.com.br 